\title{
The Sodium Ion Affinities of Simple Di-, Tri-, and Tetrapeptides
}

\author{
Ping Wang and Chrys Wesdemiotis \\ Department of Chemistry, University of Akron, Akron, Ohio, USA

\section{Catherine Kapota and Gilles Ohanessian} \\ Laboratoire des Mécanismes Réactionnels, CNRS, Ecole Polytechnique, Palaiseau, France
}

The sodium ion affinities (binding energies) of nineteen peptides containing 2-4 residues have been determined by experimental and computational approaches. $\mathrm{Na}^{+}$-bound heterodimers with amino acid and peptide ligands $\left(\mathrm{Pep}_{1}, \mathrm{Pep}_{2}\right)$ were produced by electrospray ionization. The dissociations of these $\mathrm{Pep}_{1}-\mathrm{Na}^{+}-\mathrm{Pep}_{2}$ ions to $\mathrm{Pep}_{1}-\mathrm{Na}^{+}$and $\mathrm{Pep}_{2}-\mathrm{Na}^{+}$were examined by collisionally activated dissociation to construct a ladder of relative affinities via the kinetic method. The accuracy of this ladder was subsequently ascertained by experiments using several excitation energies for four peptide pairs. The relative scale was converted to absolute affinities by anchoring the relative values to the known $\mathrm{Na}^{+}$affinity of GlyGly. The $\mathrm{Na}^{+}$ affinities of AlaAla, HisGly, GlyHis, GlyGlyGly, AlaAlaAla, GlyGlyGlyGly, and AlaAlaAlaAla were also calculated at the MP2(full)/6-311 $+G(2 d, 2 p)$ level of ab initio theory using geometries that were optimized at the MP2(full)/6-31G(d) level for AlaAla or HF/6-31G(d) level for the other peptides; the resulting values agree well with experimental $\mathrm{Na}^{+}$affinities. Increasing the peptide size is found to dramatically augment the $\mathrm{Na}^{+}$binding energy. The calculations show that in nearly all cases, all available carbonyl oxygens are sodium binding sites in the most stable structures. Whenever side chains are available, as in HisGly and GlyHis, specific additional binding sites are provided to the cation. Oligoglycines and oligoalanines have similar binding modes for the di- and tripeptides, but differ significantly for the tetrapeptides: while the lowest energy structure of GlyGlyGlyGly-Na${ }^{+}$has the peptide folded around the ion with all four carbonyl oxygens in close contact with $\mathrm{Na}^{+}$, that of AlaAlaAlaAla- $\mathrm{Na}^{+}$involves a pseudo-cyclic peptide in which the $\mathrm{C}$ and $\mathrm{N}$ termini interact via hydrogen bonding, while $\mathrm{Na}^{+}$sits on top of the oxygens of three nearly parallel $\mathrm{C}=\mathrm{O}$ bonds. (J Am Soc Mass Spectrom 2007, 18, 541-552) () 2007 American Society for Mass Spectrometry

S odium ion is the most important electrolyte in biological systems. Its interactions with proteins play an essential role in the regulation of body fluids as well as in cellular metabolism and the stabilization of biomolecular conformations [1-4]. For a better understanding of the biological functions of $\mathrm{Na}^{+}$, thermochemical and structural information about the intrinsic $\mathrm{Na}^{+}$binding modes to suitable model systems is necessary. Complexes of sodium ion with amino acids and simple peptides are most appropriate model systems.

There have been several studies on the $\mathrm{Na}^{+}$affinities of amino acids [5-16], but studies with peptides are scarce. Klassen et al. subjected the GlyGly- $\mathrm{Na}^{+}$complex to threshold collision-induced dissociation (TCID) experiments, which resulted in a $\mathrm{Na}^{+}$affinity $\left(\Delta \mathrm{H}_{\mathrm{Na}}\right)$ of $179 \pm 10 \mathrm{~kJ} / \mathrm{mol}$ at $298 \mathrm{~K}$ [6]. Cerda and coworkers [17]

Published online December 8, 2006

Address reprint requests to Dr. C. Wesdemiotis, Department of Chemistry, The University of Akron, Akron, $\mathrm{OH}$ 44325-3601, USA. E-mail: wesdemiotis@uakron.edu measured a similar value, $177 \pm 10 \mathrm{~kJ} / \mathrm{mol}$, using the extended kinetic method [18, 19] and the nucleobases adenine, cytosine, and guanine as reference bases; the same authors also investigated alanine containing dipeptides, which were shown to bind $\mathrm{Na}^{+}$slightly more strongly than GlyGly [17]. Feng et al. [20] assessed the relative free energies of $\mathrm{Na}^{+}$binding for a series of GlyXxx dipeptides by the classical kinetic method [21], but did not convert the experimental results to binding enthalpies due to the lack of entropic data. Finally, a more recent extended kinetic method study by Kish et al. [22] paired GlyGly with amino acids and derived a $\mathrm{Na}^{+}$affinity of $203 \pm 8 \mathrm{~kJ} / \mathrm{mol}$.

$\mathrm{Ab}$ initio calculations at the MP2/6-311 + $\mathrm{G}(2 \mathrm{~d}, 2 \mathrm{p}) / / \mathrm{HF} / 6-31 \mathrm{G}(\mathrm{d})$ level of theory, including basis set superposition error (BSSE) corrections, predicted a GlyGly- $\mathrm{Na}^{+}$bond enthalpy of $190 \mathrm{~kJ} / \mathrm{mol}$ at $298 \mathrm{~K}$ [17]. Recent computational work has demonstrated, however, that affinities obtained at a high level of ab initio theory, similar to the one mentioned, lie closer to true binding energies if no BSSE correction is performed $[11,12,23,24]$. Recalculation of $\Delta \mathrm{H}_{\mathrm{Na}}$ (GlyGly) at the 
even higher MP2(full)/6-311+G(2d,2p)//MP2(full)/631G(d) level without BSSE correction led to a GlyGly$\mathrm{Na}^{+}$bond enthalpy of $200 \mathrm{~kJ} / \mathrm{mol}$ [22], which coincides only with the kinetic method value deduced by Kish et al. from GlyGly-Na ${ }^{+}-\mathrm{R}_{\mathrm{i}} \quad\left(\mathrm{R}_{\mathrm{i}}=\right.$ amino acids $)$ heterodimers [22].

It has been argued [22] that the underestimation of $\Delta \mathrm{H}_{\mathrm{Na}}$ (GlyGly) by Klassen et al. [6] was caused by incomplete thermalization of GlyGly- $\mathrm{Na}^{+}$before TCID and/or the use of incorrect parameters in the modeling procedure necessary to convert experimental threshold energies to $298 \mathrm{~K}$ binding enthalpies. The underestimation of $\Delta \mathrm{H}_{\mathrm{Na}}$ (GlyGly) by Cerda et al. [17] was ascribed to the rigid and planar structures of the nucleobase reference bases used, which could prevent the formation of the most strongly bound GlyGly- $\mathrm{Na}^{+}$conformer upon heterodimer dissociation. A further reason for the low $\Delta \mathrm{H}_{\mathrm{Na}}$ (GlyGly) value of Cerda et al. [17] could be the markedly different $\mathrm{Na}^{+}$binding modes of GlyGly versus the reference bases adenine, cytosine, and guanine, reflected by the considerable difference in $\mathrm{Na}^{+}$ binding entropy between GlyGly and these nucleobases [22]; kinetic method experiments have been shown to yield underestimated affinities in such cases [25-28].

In the present investigation, the relative sodium ion affinities of a series of di-, tri-, and tetrapeptides are determined by the kinetic method for the first time and anchored to the experimental $\mathrm{Na}^{+}$affinity of GlyGly that is in accord with the theoretical prediction (i.e., 203 $\pm 8 \mathrm{~kJ} / \mathrm{mol}$ ) to derive a scale of absolute $\mathrm{Na}^{+}$binding energies. Additionally, for AlaAla, GlyHis, HisGly, GlyGlyGly, AlaAlaAla, GlyGlyGlyGly, and AlaAlaAlaAla, binding modes and sodium ion affinities are calculated at a high ab initio level including electron correlation but excluding BSSE correction. The very good agreement found between computed and experimental $\mathrm{Na}^{+}$affinities validates the choice of $\Delta \mathrm{H}_{\mathrm{Na}}$ $($ GlyGly $)=203 \pm 8 \mathrm{~kJ} / \mathrm{mol}$, measured previously by Kish et al. [22], as anchor for the conversion of experimental relative energies into absolute $\mathrm{Na}^{+}$affinities. Further, the derived affinity map provides new insight about the binding modes of side chain versus backbone substituents and should be helpful for the estimation of the unknown sodium ion affinities of similarly sized peptides.

\section{Methods}

\section{Mass Spectrometry Experiments}

The gas-phase sodium ion bound heterodimers $\left(\mathrm{Pep}_{1}{ }^{-}\right.$ $\mathrm{Na}^{+}-\mathrm{Pep}_{2}$ ) were formed by electrospray ionization (ESI) and their competitive dissociations to the metalated monomers were examined by collisionally activated dissociation (CAD) in a quadrupole ion trap mass spectrometer (Bruker Esquire-LC, Billerica, MA). The ESI solvent used was a 2:1 (vol:vol) mixture of water and methanol. One mg of each amino acid, peptide, and sodium trifluoroacetate (NaTFA) was dissolved in $1 \mathrm{~mL}$ of solvent. Salt:Pep $\mathrm{P}_{1} \mathrm{Pep}_{2}$ solutions were combined in the ratio $0.75: 1: 1$ to make the sprayed solution. The latter solution was introduced into the ion source by a syringe pump at a rate of $240 \mu \mathrm{L} / \mathrm{h}$. The spraying needle was grounded and the entrance of the sampling capillary was set at $-4 \mathrm{kV}$. Nitrogen was used as the nebulizing gas $(10 \mathrm{psi})$ and drying gas $\left(8 \mathrm{~L} / \mathrm{min}, 160^{\circ} \mathrm{C}\right)$ and $\mathrm{He}$ as the buffer gas in the ion trap $\left(\sim 10^{-5} \mathrm{mbar}\right)$. The precursor dimer ions were isolated and excited to fragment in the ion trap for CAD with a rf that was resonant with their frequency of motion in the trap. The excitation time was $40 \mathrm{~ms}$ and the RF amplitude $\left(\mathrm{V}_{p-p}\right)$ was adjusted in the 0.32 to $0.55 \mathrm{~V}$ range to maximize the abundance of the sodiated monomers without causing appreciable competitive and/or consecutive dissociations $(<16 \%$ of total fragment ions arose from the latter processes). Thirty scans per spectrum were collected and the experiments were reproduced three times. The solvents (water, methanol; HPLC grade) were supplied by Sigma-Aldrich (St. Louis, MO) and NaTFA by Aldrich (Milwaukee, WI). The amino acids Pro (P), Thr $(\mathrm{T})$, Phe $(\mathrm{F})$, and Trp $(\mathrm{W})$, and the peptides GlyGly (GG), AlaGly (AG), GlyAla (GA), AlaAla (AA), GlyLeu (GL), SerGly (SG), AlaTrp (AW), TrpAla (WA), GlyGlyGly (GGG), AlaGlyGly (AGG), GlyHis (GH), LeuGlyPhe (LGF), HisGly (HG), GlyHisGly (GHG), and GlyGlyGlyGly (GGGG) were purchased from Sigma (St. Louis, MO). The peptides GlyPhe (GF), PheGly (FG), AlaAlaGly (AAG), AlaAlaAla (AAA), and AlaAlaAlaAla (AAAA) were purchased from Bachem (King of Prussia, PA). All chemicals were used without further purification. The amino acids and peptides used in this study were chosen based on their side chains and their ability to form $\mathrm{Na}^{+}$-bound heterodimers.

\section{Kinetic Method}

The kinetic method experiments involved formation of gaseous $\mathrm{Pep}_{1}-\mathrm{Na}^{+}-\mathrm{Pep}_{2}$ dimers and subsequent CAD of these dimers to the sodiated monomers according to eq 1. For simplicity, the abbreviation Pep is used here for both peptides and amino acids. The abundance ratio of the $\mathrm{Pep}_{1}-\mathrm{Na}^{+}$and $\mathrm{Na}^{+}-\mathrm{Pep}_{2}$ fragments in the resulting CAD spectrum represents an approximate measure of the rate constant ratio $\left(k_{1} / k_{2}\right)$ of the dissociations leading to these fragment ions. This assumption presupposes that other competing pathways and mass discrimination effects are negligible. Based on the thermodynamic formulation of transition-state theory [29], the natural logarithm of $k_{1} / k_{2}$ is a function of the relative free-energy of activation of the two competing dissociations of the heterodimers, as shown in eq 2, where $\mathrm{R}$ is the ideal gas constant and $\mathrm{T}_{\text {eff }}$ is the effective temperature of the dissociating dimer ions [19]. The enthalpy and entropy components of the free energies are included in eq 2. The unimolecular reactions shown in eq 1 involve cleavages of electrostatic bonds, which generally proceed without appreciable reverse activation energy $[5,6,17,21,30-32]$. In such cases, the relative 
enthalpy of activation becomes equivalent (with opposite sign) to the difference in binding enthalpies of $\mathrm{Na}^{+}$ to $\mathrm{Pep}_{1}$ and $\mathrm{Pep}_{2}$, cf. eq 3, where the $\mathrm{Na}^{+}$binding enthalpy or $\mathrm{Na}^{+}$affinity (also called $\mathrm{Na}^{+}$binding energy) is defined as the enthalpy change, $\Delta \mathrm{H}_{\mathrm{Na}}$, of the reaction Pep- $\mathrm{Na}^{+} \rightarrow$ Pep $+\mathrm{Na}^{+}$. Analogously, the relative activation entropy can be replaced by an apparent relative entropy [33] of the $\mathrm{Pep}_{1}-\mathrm{Na}^{+}$and $\mathrm{Na}^{+}-\mathrm{Pep}_{2}$ bonds.

$$
\begin{aligned}
& \mathrm{Pep}_{1}-\mathrm{Na}^{+}+\mathrm{Pep}_{2} \leftarrow \mathrm{Pep}_{1}-\mathrm{Na}^{+}-\mathrm{Pep}_{2} \stackrel{k_{2}}{\rightarrow} \mathrm{Pep}_{1}+\mathrm{Na}^{+} \\
& -\mathrm{Pep}_{2} \\
& \ln \left(k_{1} / k_{2}\right)=-\left[\Delta \mathrm{G}_{1}^{\ddagger}-\Delta \mathrm{G}_{2}^{\ddagger}\right] / \mathrm{RT}_{\mathrm{eff}}=\left[\Delta \mathrm{S}_{1}^{\ddagger}-\Delta \mathrm{S}_{2}^{\ddagger}\right] / \mathrm{R} \\
& -\left[\Delta \mathrm{H}_{1}^{\ddagger}-\Delta \mathrm{H}_{2}^{\ddagger}\right] / \mathrm{RT}_{\mathrm{eff}} \\
& \ln \left(k_{1} / k_{2}\right)=-\left[\Delta \mathrm{S}_{\mathrm{Na}}\left(\operatorname{Pep}_{1}\right)-\Delta \mathrm{S}_{\mathrm{Na}}\left(\mathrm{Pep}_{2}\right)\right] / \mathrm{R} \\
& +\left[\Delta \mathrm{H}_{\mathrm{Na}}\left(\mathrm{Pep}_{1}\right)-\Delta \mathrm{H}_{\mathrm{Na}}\left(\mathrm{Pep}_{2}\right)\right] / \mathrm{RT}_{\mathrm{eff}}=-\Delta\left(\Delta \mathrm{S}_{\mathrm{Na}}\right) / \mathrm{R} \\
& +\left[\Delta \mathrm{H}_{\mathrm{Na}}\left(\mathrm{Pep}_{1}\right)-\Delta \mathrm{H}_{\mathrm{Na}}\left(\mathrm{Pep}_{2}\right)\right] / \mathrm{RT}_{\mathrm{eff}} \\
& \ln \left(k_{1} / k_{2}\right) \approx\left[\Delta \mathrm{H}_{\mathrm{Na}}\left(\mathrm{Pep}_{1}\right)-\Delta \mathrm{H}_{\mathrm{Na}}\left(\mathrm{Pep}_{2}\right)\right] / \mathrm{RT}_{\mathrm{eff}} \\
& =\Delta\left(\Delta \mathrm{H}_{\mathrm{Na}}\right) / \mathrm{RT}_{\mathrm{eff}}
\end{aligned}
$$

Because the $\mathrm{Na}^{+}$-bound dimers are not in thermal equilibrium with their surroundings and their internal energy distributions are not Boltzmann-shaped [18, 22, 33-34], an effective temperature and apparent entropy difference are used instead of a thermodynamic temperature and entropy difference. On the basis of recent studies $[12,22,33-36], \Delta\left(\Delta S_{\mathrm{Na}}{ }^{\text {app }}\right)$ depends on the identity of the decomposing dimer ions and on $\mathrm{T}_{\text {eff }}$ and its value can range from $\sim 0$ to the corresponding actual (thermodynamic) entropy difference of the bonds compared in the $\mathrm{Na}^{+}$-bound dimer. The peptides used (vide infra) will be shown to have very similar apparent $\mathrm{Na}^{+}$ entropies; when $\Delta\left(\Delta \mathrm{S}_{\mathrm{Na}}{ }^{\text {app }}\right) \approx 0$, eq 3 is simplified to eq 4 , which relates the experimental $k_{1} / k_{2}$ data to relative $\mathrm{Na}^{+}$binding affinities. Relative sodium ion affinities obtained through the examination of $\mathrm{Pep}_{1}-\mathrm{Na}^{+}-\mathrm{Pep}_{2}$ dimers can be converted to absolute $\Delta \mathrm{H}_{\mathrm{Na}}$ data if the relative values are anchored to a known $\mathrm{Na}^{+}$binding energy.

\section{Calculations}

$\mathrm{Ab}$ initio calculations were carried out at levels which have been shown in previous work to provide reasonably accurate geometries and sodium ion affinities [37]. Geometries were optimized at the HF/6$31 G(d)$ level; vibrational analyses were carried out at the same level to determine zero-point vibrational energies, thermal corrections to total energies, and entropies. All frequencies were found to be real as expected; no special treatment was applied to hindered rotors. Final energetics were determined at the MP2(full)/6-311+G(2d,2p) level using the HF/6-
31G(d) geometries [11, 12, 22]. Extensive comparison with MP2(full)/6-31G(d) geometries has been done in previous work; both levels were shown to yield very similar results. No BSSE corrections were performed for the reason mentioned in the introduction [22-24]. Comparison with final energetics at the MP2/aug-ccpVTZ level has shown this procedure to be converged with respect to basis set extension to within $<5$ $\mathrm{kJ} / \mathrm{mol}[12]$.

While the structures of bare and sodiated amino acids studied previously could be determined by constructing guesses based on chemical intuition, this becomes less appropriate as the peptide grows bigger. The sodium complexes remain relatively easy to study, since the ion charge provides a structuring effect, leading to peptide wrapping to maximize ion chelation. It was found, however, that even for dipeptide complexes such as GlyHis- $\mathrm{Na}^{+}$and HisGly- $\mathrm{Na}^{+}$, systematic searches become necessary to locate all low-energy structures. This is even truer for bare peptides, in which the main structuring effect is a network of hydrogen bonds, which quickly becomes very difficult to guess exhaustively. Thus, we resorted to a nonlocal exploration of the potential energy surface, as a preliminary step before local geometry optimization with the $a b$ initio methods mentioned above. Monte Carlo sampling with the Metropolis criterion was carried out, in which random values were generated for the torsion angles around all single bonds between nonhydrogen atoms except the peptide bonds. To keep this procedure computationally tractable, simplified energy calculations were made using the Amber 94 force field with RESP atomic charges [38]. Random sampling was systematically followed by local geometry optimization at the same level. Several independent runs were carried out in each case, with a limit of 500 geometry optimizations for each, after elimination of structures bearing close contacts. The Amber 94 force field leads to an energy ordering of isomers and conformers which may deviate significantly from that obtained with accurate ab initio calculations. To locate all low lying structures, a large sample of the most stable structures arising from each Monte Carlo search was selected and subjected to geometry reoptimization at the HF/6-31G(d) level, typically between 10 and 20 distinct structures. Systematic searches were not performed for oligoalanine peptides. The several most stable structures obtained for each oligoglycine were taken and the appropriate hydrogens transformed into methyl groups; typically the four to five most stable conformers were included, to ensure that the most stable conformer of the corresponding oligoalanine was identified. Sodium is a stereogenic center in such complexes; therefore, diastereomers were generated as described in the Results section. Monte Carlo calculations were carried out with HyperChem 6.0 [39], while ab initio calculations used the Gaussian 03 suite of programs [40]. 


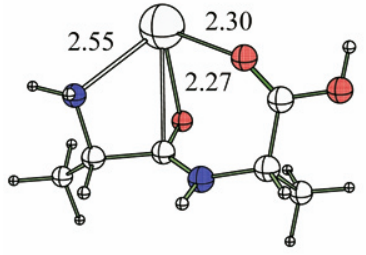

$\mathrm{AA}-\mathrm{Na}^{+} \mathbf{1 a}(0)$

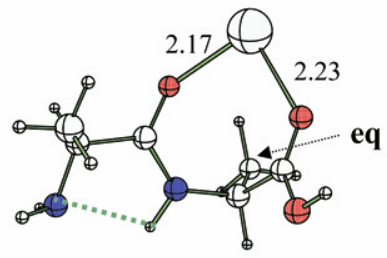

$\mathrm{AA}-\mathrm{Na}^{+} \mathbf{2 a}(+2)$

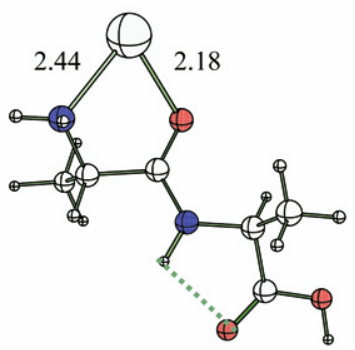

$\mathrm{AA}-\mathrm{Na}^{+} \mathbf{3}(+14)$

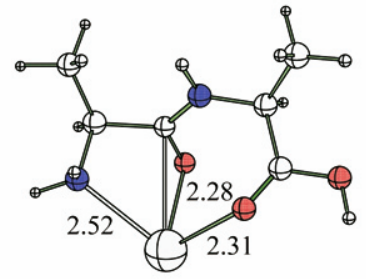

AA- $-\mathrm{Na}^{+} \mathbf{1 b}(+3)$

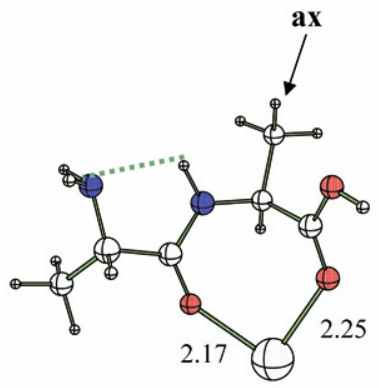

$\mathrm{AA}-\mathrm{Na}^{+} \mathbf{2 b}(+10)$

Figure 1. AlaAla- $\mathrm{Na}^{+}$isomers with L-alanine. $\mathbf{1 a} / \mathbf{1} \mathbf{b}$ and $\mathbf{2 a} / \mathbf{2} \mathbf{b}$ are diastereomers differing in the orientation of the methyl side chains; eq and ax denote roughly equatorial and roughly axial positions, respectively. The numbers next to the bonds give bond lengths in $\AA$; the numbers in parenthesis are relative energies in $\mathrm{kJ} / \mathrm{mol}$.

\section{Results}

\section{Ab Initio Calculations for Oligoglycines and Oligoalanines and Their Sodium Complexes}

The potential energy surfaces for both the sodiated and bare species have been explored. Although the conformers of the bare peptides were searched previously, we have found new, lower-energy structures for the triand tetrapeptides. Sodiated GlyGly [15, 16, 41], and potassiated GlyGly and AlaAla [42] were also studied in earlier work, and a nonexhaustive study of sodiated GlyGlyGly and GlyGlyGlyGly was published [43]. In these cases, too, the structures reported herein are of lower energy than those previously reported. The present investigation appears to be the first on sodiated tri- and tetraalanines.

The low-energy structures of GlyGly-Na ${ }^{+}$, GlyGly$\mathrm{K}^{+}$, and GlyGly have been studied extensively $[17,42]$. For GlyGly- $\mathrm{Na}^{+}$, there are two low-energy geometries of essentially identical energies, both involving chelation of sodium ion to both carbonyl oxygens. They differ in the orientation of the $\mathrm{NH}_{2}$ terminus, which may either provide a third chelation site, or interact with the peptide NH bond. The latter was found to have a slightly more favorable entropy of complexation [17]. The computed $\mathrm{Na}^{+}$binding enthalpies of both structures were too close to be distinguished on the basis of experimental results [17]. A few additional structures have been found to be of relatively low-energy (al- though they are unlikely to be formed experimentally), including one in which $\mathrm{Na}^{+}$is bound to the amino nitrogen and to the carbonyl oxygen of the peptide bond. When these three structures were used to generate isomers of AlaAla- $\mathrm{Na}^{+}$, the same energy order was obtained, in agreement with the results of Tsang et al. for AlaAla- $\mathrm{K}^{+}$[42]. There is, however, a significant difference between oligoglycines and oligoalanines: the sodium ion binding is strong enough that sodium may be regarded as a stereogenic center. Consider for instance isomers $\mathbf{1 a}$ and $\mathbf{1 b}$ of AlaAla-Na ${ }^{+}$(Figure 1). The central carbonyl may lie on either side of the plane defined by $\mathrm{Na}^{+}$, the carbonyl oxygen at the $\mathrm{C}$ terminus and the $\mathrm{N}$ terminus. This generates two structures, which may be considered as diastereomers. In $\mathbf{2 a}$ and $\mathbf{2 b}$, it is the puckering of the chelate ring that is inverted. When the two carbonyl groups bound to sodium ion are nearly coplanar, the methyl positions may be described as roughly axial and equatorial with respect to the seven-membered pseudo-cycle generated by $\mathrm{Na}^{+}$chelation. This leads to a significant energy difference, e.g., $8 \mathrm{~kJ} / \mathrm{mol}$ between $\mathbf{2 a}$ and $\mathbf{2 b}$. When the two consecutive $\mathrm{C}=\mathrm{O}$ groups are far from coplanar, as in isomer $\mathbf{1}$, the two possible methyl positions become more similar and, thus, the energy difference is also smaller; e.g., 3 $\mathrm{kJ} / \mathrm{mol}$ between $\mathbf{1 a}$ and $\mathbf{1 b}$. As a result of these effects, the two lowest energy structures are $\mathbf{1 a}$ and $\mathbf{2 a}$, the next two are the less stable diastereomers $\mathbf{1 b}$ and $\mathbf{2} \mathbf{b}$, and the fifth is isomer 3 , in which $\mathrm{Na}^{+}$is not stereogenic 


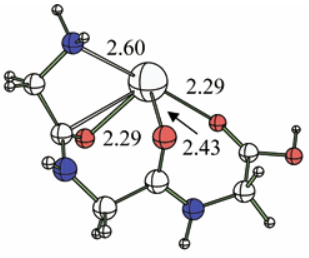

GGG-Na ${ }^{+} 1(0)$

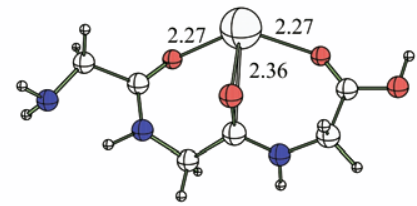

GGG-Na+ $3(+2)$

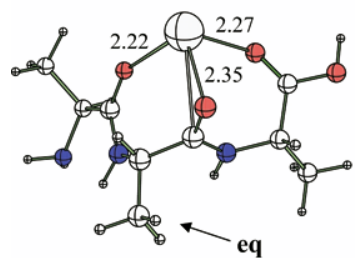

$\mathrm{AAA}-\mathrm{Na}^{+} \mathbf{2 a}(0)$

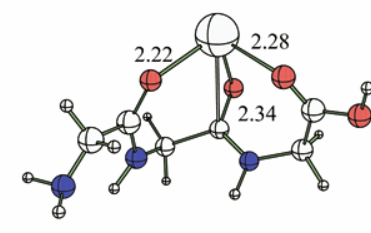

GGG-Na+ $2(0)$

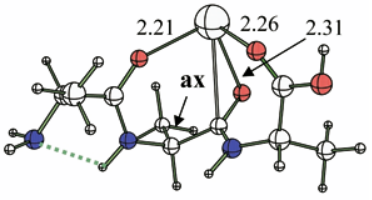

$\mathrm{AAA}-\mathrm{Na}^{+} \mathbf{2 b}(+7)$
Figure 2. Most stable conformers of the GlyGlyGly- $\mathrm{Na}^{+}$and AlaAlaAla- $\mathrm{Na}^{+}$complexes; $\mathbf{2} \mathbf{a} / \mathbf{2} \mathbf{b}$ are diastereomers differing in the orientation of the L-alanine side chains. The numbers next to the bonds give bond lengths in $\AA$; the numbers in parenthesis are relative energies in $\mathrm{kJ} / \mathrm{mol}$.

because sodium ion chelation generates a nearly planar five-membered ring. (Figure 1).

In agreement with Bowers and coworkers [44], the most stable structures of GlyGlyGly- $\mathrm{Na}^{+}$are found to have all three carbonyls interacting with the sodium ion (Figure 2). As with the dipeptides, additional binding of the amino terminus to the ion (isomer 1) leads to a binding enthalpy that is essentially equal to that of isomer $\mathbf{2}$ in which the amine group is folded towards the next amide $\mathrm{N}-\mathrm{H}$ bond. Isomer 3 also has the three carbonyl oxygens as sodium ligands; it differs from 2 by the conformation of the peptide backbone, which is more folded in 2, leading to the $\mathrm{Na}-\mathrm{O}$ bond closest to the $\mathrm{N}$ terminus being shorter than in $\mathbf{3}$ and, thus, to a slightly more favorable enthalpy of binding. The enthalpy of $\mathbf{3}$ at $298 \mathrm{~K}$ is higher than that of 2 by only 2 $\mathrm{kJ} / \mathrm{mol}$. Consequently, our computations predict that a mixture of isomers 1, 2, and 3 should be formed experimentally. The next most stable structure (not shown) involves a folded peptide with a hydrogen bond from the carboxyl to the amino terminus, and the sodium ion bound to the three carbonyls in a nearly parallel orientation. This isomer is less stable than 1 by $23 \mathrm{~kJ} / \mathrm{mol}$. A number of other structures have been fully characterized, but all are higher in energy.

The distinction between diastereomers discussed above for AlaAla- $\mathrm{Na}^{+}$must be extended to AlaAlaAla-
$\mathrm{Na}^{+}$. As with AlaAla-Na ${ }^{+}$, the energy splitting between stereoisomers strongly varies with the type of structure considered. Here, the most stable structure derives from isomer 2 of GlyGlyGly- $\mathrm{Na}^{+}$. As shown in Figure 2, diastereomer 2a contains a pseudo-equatorial methyl group, which is axial in diastereomer $\mathbf{2 b}$. This leads to an enthalpy difference of $7 \mathrm{~kJ} / \mathrm{mol}$ in favor of 2a. The latter is lower in energy than both diastereomers with the amino terminus bound to sodium ion (as in isomer $\mathbf{1}$ of GlyGlyGly-Na${ }^{+}$), by 2 to $3 \mathrm{~kJ} / \mathrm{mol}$. It is also more stable than both diastereomers with the GlyGlyGly- $\mathrm{Na}^{+} 3$ backbone, by 9 to $10 \mathrm{~kJ} / \mathrm{mol}$. Note that the energy splitting between AlaAlaAla- $\mathrm{Na}^{+}$stereoisomers amounts to less than $1 \mathrm{~kJ} / \mathrm{mol}$ for both $1 \mathrm{a}$ and $\mathbf{1 b}$ as well as $\mathbf{3 a}$ and $\mathbf{3} \mathbf{b}$. All other isomers are significantly less stable, as for GlyGlyGly- $\mathrm{Na}^{+}$.

The conformers of bare GlyGlyGly have been studied by Strittmatter and Williams [45], who found that the most stable one involves a $\gamma$ turn between the two peptide linkages. Hopkinson et al. [46] have reconsidered the conformers of GlyGlyGly and found a lower energy structure which contains a $\gamma$ turn as well as a hydrogen bond between the amino terminus and the carbonyl oxygen of the $\mathrm{C}$ terminus. As shown in Figure 3 , our own calculations lead to the same result for

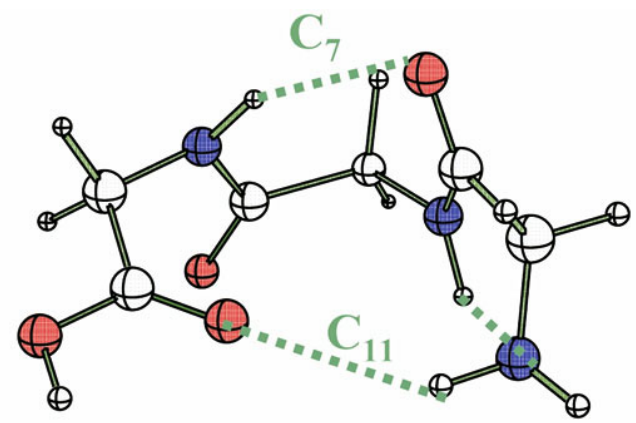

GGG 1

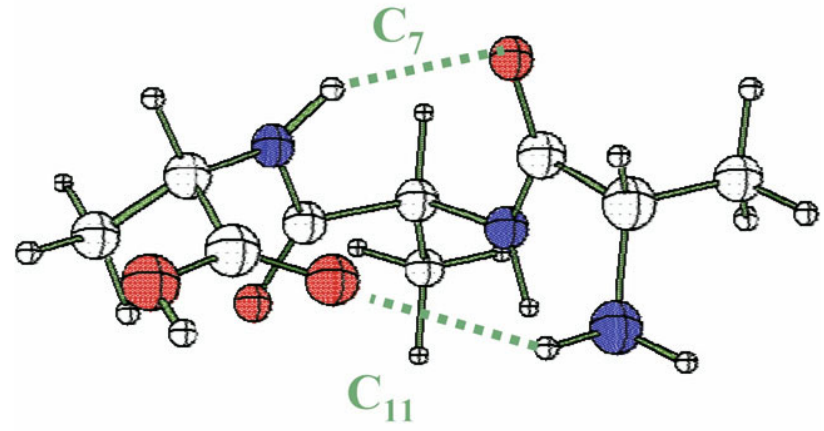

AAA 1a

Figure 3. Lowest-energy conformers of bare GlyGlyGly and AlaAlaAla. " $\mathrm{C}_{\mathrm{n}}$ " indicates that an $n$-membered pseudo-cycle is formed by hydrogen bonding. $C_{7}$ is equivalent to a $\gamma$ turn. 


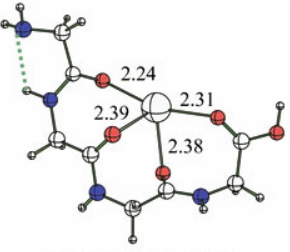

GGGG-Na+ $1(0)$

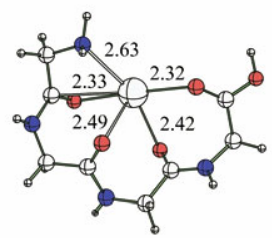

GGGG-Na ${ }^{+} 3(+4)$

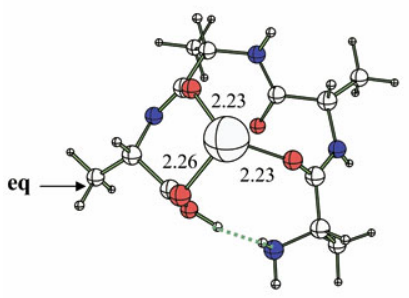

AAAA- $\mathrm{Na}^{+} 4 \mathbf{a}(0)$

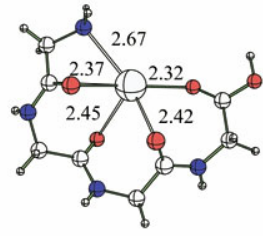

GGGG-Na+ $2(+3)$

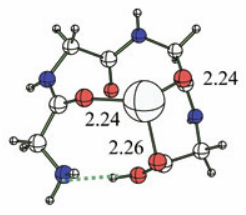

GGGG-Na $4(+12)$

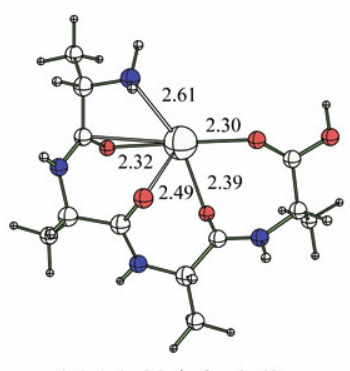

AAAA $-\mathrm{Na}^{+} 3 \mathbf{a}(+1)$
Figure 4. Most stable conformers of the GlyGlyGlyGly- $-\mathrm{Na}^{+}$and AlaAlaAlaAla- $\mathrm{Na}^{+}$complexes. The numbers next to the bonds give bond lengths in $\AA$; the numbers in parenthesis are relative energies in $\mathrm{kJ} / \mathrm{mol}$.

GlyGlyGly, and find a completely analogous conformer for AlaAlaAla.

The lowest energy structures of GlyGlyGlyGly-Na ${ }^{+}$ follow the same trends as those of the smaller peptides, in that they involve chelation of sodium ion to all carbonyl oxygens (Figure 4). Here we find that the most stable structure, $\mathbf{1}$, does not involve binding of the amino terminus to $\mathrm{Na}^{+}$; however structures 2 and 3, which do, are only 3 and $4 \mathrm{~kJ} / \mathrm{mol}$ higher in energy, respectively. The latter two differ by the relative positions of the various $\mathrm{C}=\mathrm{O}$ bonds relative to the average backbone plane. Isomer 4 has the peptide folded onto itself so as to allow for a hydrogen bond from the $C$ to the $\mathrm{N}$ terminus. It is $12 \mathrm{~kJ} / \mathrm{mol}$ less stable than $\mathbf{1}$, a value that is significantly smaller than the $23 \mathrm{~kJ} / \mathrm{mol}$ found for the analogous difference in GlyGlyGly- $\mathrm{Na}^{+}$. This has a strong impact on the relative energies of isomers for AlaAlaAlaAla- $\mathrm{Na}^{+}$. This folded structure generates diastereomers with a $8 \mathrm{~kJ} / \mathrm{mol}$ energy difference, with the equatorial case being the most stable of all AlaAlaAlaAla- $\mathrm{Na}^{+}$isomers (see 4a in Figure 4). Clearly this capped structure generates the smallest steric strain for the four methyl groups. The next most stable isomer is $3 \mathbf{a}$, only $1 \mathrm{~kJ} / \mathrm{mol}$ higher in energy than $4 \mathbf{a}$, while the five next structures (derived from 1, 2, and 3 of GlyGlyGly- $\mathrm{Na}^{+}$) are within $4 \mathrm{~kJ} / \mathrm{mol}$ of the most stable isomer $\mathbf{4 a}$.
For GlyGlyGlyGly, the lowest energy structure found by Strittmatter and Williams [45] involves two $\gamma$ turns and an $\mathrm{O}-\mathrm{H}-\mathrm{N}$ hydrogen bond from the $\mathrm{C}$ terminal $\mathrm{OH}$ group to the nitrogen of the $\mathrm{N}$ terminus. We have identified two conformers that lie lower in energy at the MP2/6-311 + G(2d,2p)//HF/6-31G(d) level. The most stable (see $\mathbf{1}$ in Figure 5) is very closely related to the above, the only significant difference being the $\mathrm{O}-\mathrm{H}-\mathrm{N}$ bond between the carbonyl oxygen of the $\mathrm{C}$ terminus and one of the $\mathrm{NH}$ bonds of the $\mathrm{N}$ terminus. This is found to be the lowest energy structure; however, the next isomer ( 2 in Figure 5 ) is only 1 $\mathrm{kJ} / \mathrm{mol}$ higher in energy. It has the same interaction between the two termini, but the peptide folding generates a $\beta$ and a $\gamma$ turn, instead of the two $\gamma$ turns in $\mathbf{1 .}$ Many other conformers were fully characterized, the next most stable being $11 \mathrm{~kJ} / \mathrm{mol}$ less stable than 1 . The energetic picture is very similar in AlaAlaAlaAla, if the most stable diastereomer is considered in each case. The energy difference between isomers $\mathbf{1 a}$ and $\mathbf{2 a}$ is 0.3 $\mathrm{kJ} / \mathrm{mol}$; therefore, here again, the calculations cannot provide a definitive conclusion as to which structure is the most stable, and likely they coexist in the gas phase.

\section{Ab Initio Calculations for HisGly and GlyHis and Their Sodium Complexes}

The sodium affinities of several pairs of isomeric dipeptides, differing by their amino acid sequences, have been determined experimentally (vide infra). Within this subgroup, we have considered in detail the dipeptide pair HisGly and GlyHis, for which the sequence effect on $\mathrm{Na}^{+}$affinity was measured to be the largest. The structures and relative energies of both peptides and of their sodium ion complexes have been described in detail elsewhere [47]. We focus here on the features
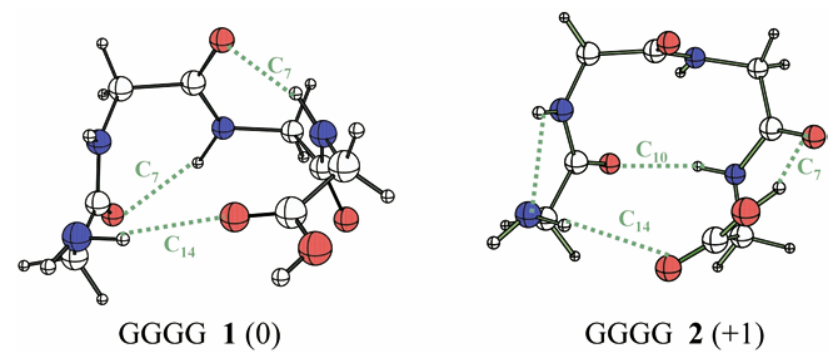

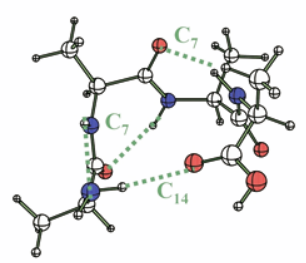

AAAA 1 a (0)

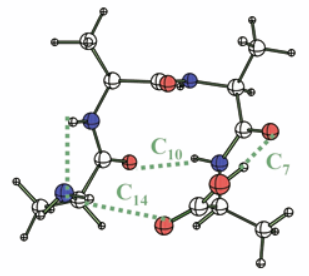

AAAA 2a (0)
Figure 5. Most stable conformers of bare GlyGlyGlyGly and AlaAlaAlaAla. The numbers in parenthesis give relative energies in $\mathrm{kJ} / \mathrm{mol}$. 


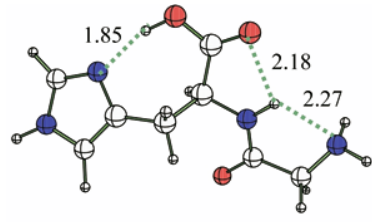

$\mathrm{GH}$

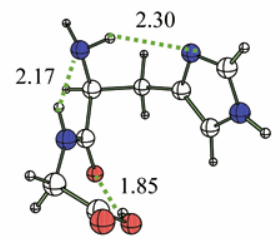

HG

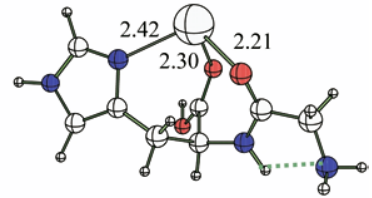

$\mathrm{GH}-\mathrm{Na}^{+}$

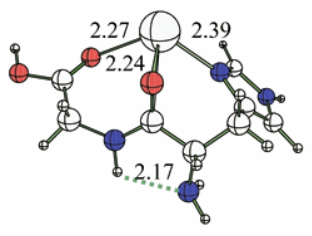

$\mathrm{HG}-\mathrm{Na}^{+}$
Figure 6. Most stable conformers of the $\mathrm{N}^{\varepsilon 2}-\mathrm{H}$ tautomers of GlyHis and HisGly and of the GlyHis- $\mathrm{Na}^{+}$and HisGly- $\mathrm{Na}^{+}$ complexes containing the $\mathrm{N}^{\varepsilon 2}-\mathrm{H}$ tautomers. The numbers next to the bonds give bond lengths in $\AA$.

which are relevant to the calculation of the $\mathrm{Na}^{+}$affinities of GlyHis and HisGly. Depending on the imidazole tautomer present in the His side chain, a His residue can exist in the $\mathrm{N}^{\delta 1}-\mathrm{H}$ or the $\mathrm{N}^{\varepsilon 2}-\mathrm{H}$ tautomeric form. In the $\mathrm{N}^{\delta 1}-\mathrm{H}$ tautomer of histidine, the imidazole nitrogen nearest to the backbone $\left(\mathrm{N}^{\delta 1}\right)$ is protonated and the other nitrogen $\left(\mathrm{N}^{\varepsilon 2}\right)$ is deprotonated; the opposite connectivity is found in the $\mathrm{N}^{\varepsilon 2}-\mathrm{H}$ tautomer. For both GlyHis and HisGly dipeptides, the lowest energy conformers of the two tautomeric forms were found to be of similar energies, yet the $\mathrm{N}^{\delta 1}-\mathrm{H}$ tautomer is more stable for GlyHis (by $1 \mathrm{~kJ} / \mathrm{mol}$ ), while it is the $\mathrm{N}^{\varepsilon 2}-\mathrm{H}$ tautomer for HisGly (by $4 \mathrm{~kJ} / \mathrm{mol}$ ) [47]. The structures of the most stable conformer of both peptides in their $\mathrm{N}^{\varepsilon 2}-\mathrm{H}$ tautomers are shown in Figure 6. Both bear a trans carboxylic group which acts as a hydrogen bond donor, in a network where the amino terminus, peptidic $\mathrm{N}-\mathrm{H}$ bond and $\mathrm{N}^{\delta 1}$ imine nitrogen of the imidazole are also involved, albeit in a different manner in the isomeric peptides. Contrary to the bare peptides, both GlyHis- $\mathrm{Na}^{+}$and HisGly- $\mathrm{Na}^{+}$are much more stable with the $\mathrm{N}^{\varepsilon 2}-\mathrm{H}$ tautomer, by 39 and $43 \mathrm{~kJ} / \mathrm{mol}$, respectively [47]. This is due to the ability of the $\mathrm{N}^{\delta 1}$ site to provide a third chelation point to $\mathrm{Na}^{+}$when it is not protonated, while the $\mathrm{N}^{\varepsilon 2}$ site is too distant for such an interaction (see Figure 6). Both complexes have the sodium ion bound to the two carbonyl oxygens and to the imidazole $\mathrm{N}^{\delta 1}$. Assuming that complex dissociation occurs experimentally without tautomerization, then two distinct sodium ion affinities may be computed for each peptide, which are markedly different because the stabilities of the $\mathrm{N}^{\delta 1}-\mathrm{H}$ and $\mathrm{N}^{\varepsilon 2}-\mathrm{H}$ tautomers are significantly different in the corresponding $\mathrm{Na}^{+}$complexes but not in the bare peptides themselves. The computed affinity values at $298 \mathrm{~K}$ are 201 and 245 $\mathrm{kJ} / \mathrm{mol}$ for GlyHis, and 219 and $260 \mathrm{~kJ} / \mathrm{mol}$ for HisGly (in their $\mathrm{N}^{\delta 1}-\mathrm{H}$ and $\mathrm{N}^{\varepsilon 2}-\mathrm{H}$ tautomers, respectively). Comparison with experimental results (vide infra) in- dicates very good agreement only with the $\mathrm{N}^{\varepsilon 2}-\mathrm{H}$ tautomer in both cases. Calculations on the peptides at their geometries in the sodium ion complexes indicate that the deformation energy of HisGly is much smaller than that of GlyHis. While the interaction energy with sodium is stronger in the latter case, it cannot compensate for the internal energy loss of the peptide, leading to the observed sequence effect in sodium ion affinity.

\section{Experimental Sodium Ion Affinity Scale of Peptides}

The CAD spectra of about $100 \mathrm{Pep}_{1}-\mathrm{Na}^{+}-\mathrm{Pep}_{2}$ heterodimers were evaluated; only 53 of them produced acceptable signal-to-noise ratio and detectable abundances for both sodiated monomers, $\mathrm{Pep}_{1}-\mathrm{Na}^{+}$and $\mathrm{Na}^{+}-\mathrm{Pep}_{2}$. Representative spectra, corresponding to AGG- $\mathrm{Na}^{+}-\mathrm{WA}$ and $\mathrm{AAG}-\mathrm{Na}^{+}-\mathrm{LGF}$, are shown in Figure 7. Most dimer ions solely undergo dissociation to the metalated monomers (Figure 7). A few heterodimers that involve side-chain functionalized amino acids or peptides also show minor losses of $\mathrm{H}_{2} \mathrm{O}$ and $\mathrm{NH}_{3}$ or consecutive dissociations from the sodiated monomers under the experimental conditions used. The relative abundances of the latter products are consistently low compared with those of the sodiated mono-

(a)

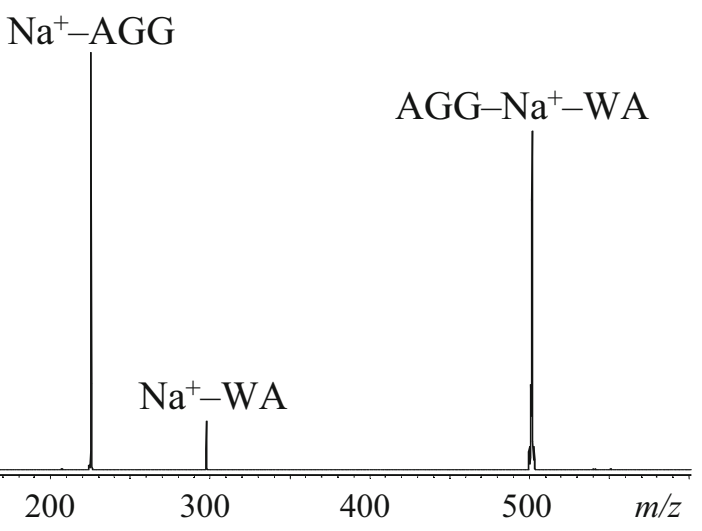

(b)

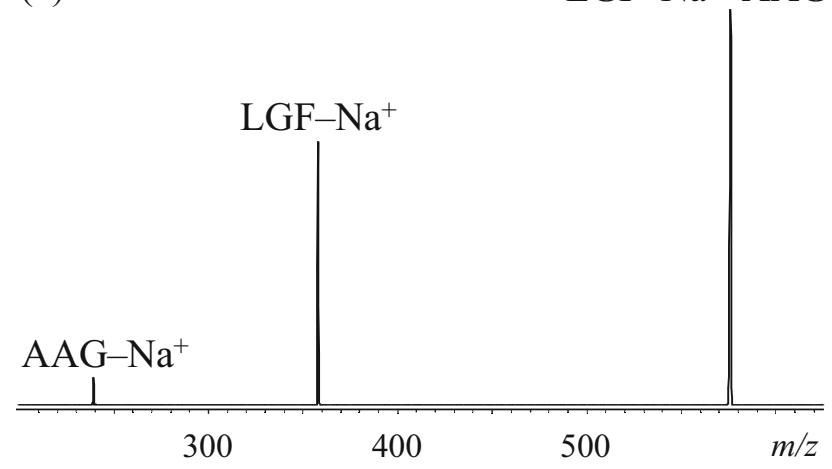

Figure 7. CAD mass spectra of heterodimers (a) AlaGlyGly$\mathrm{Na}^{+}-$TrpAla $\left(m / z\right.$ 501) and (b) AlaAlaGly- $\mathrm{Na}^{+}-$LeuGlyPhe $(\mathrm{m} / \mathrm{z}$ 575) measured at an excitation amplitude of $0.40 \mathrm{~V}$. 


\begin{tabular}{|c|c|c|c|c|c|c|c|c|}
\hline $\mathrm{P}$ & $0.48(0.03)$ & 0.59 & & 2.33 & & & & \\
\hline T & $0.26(0.04)$ & $(0.07)$ & 2.01 & $(0.05)$ & & & & \\
\hline $\mathrm{F}$ & $1.73(0.22)$ & 2.54 & $(0.06)$ & & & & & \\
\hline GG & $0.69(0.06)$ & $(0.22)$ & 1.24 & 1.65 & & 4 & & \\
\hline $\mathrm{AG}$ & & 1.15 & $(0.07)$ & $\frac{1.05}{(0.51)}$ & 1.57 & 2.33 & & \\
\hline GA & $0.52(0.04)$ & $(0.08)$ & 1.52 & & $(0.07)$ & $(0.24)$ & 2.10 & \\
\hline AA & $0.38(0.03)$ & 0.83 & $(0.07)$ & & & $\forall$ & $(0.26)$ & \\
\hline W & $0.67(0.03)$ & $(0.17)$ & & 2.55 & 1.78 & & & \\
\hline GL & $1.04(0.04)$ & 3.42 & 1.72 & $(0.08)$ & $(0.06)$ & & & \\
\hline $\begin{array}{l}\mathrm{GF} \\
\mathrm{SG}\end{array}$ & $0.46(0.03)$ & $(0.33)$ & $(0.10)$ & & & & & \\
\hline $\mathrm{FG}$ & $1.68(0.03)$ & & & & & & & \\
\hline AW & $2.19(0.11)$ & 3.16 & & & & & & \\
\hline WA & & $(0.07)$ & 3.05 & & 3.22 & & & \\
\hline GGG & $1.94(0.07)$ & 2.35 & $(0.04)$ & & $(0.27)$ & & & \\
\hline AGG & $0.36(0.08)$ & $(0.18)$ & 0.86 & 1.09 & & & & 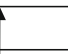 \\
\hline $\mathrm{GH}$ & $0.47(0.04)$ & 0.70 & $(0.07)$ & $(0.17)$ & & & 1.36 & 1.60 \\
\hline $\mathrm{AAG}$ & $0.28(0.04)$ & $(0.04)$ & & $\downarrow$ & 0.87 & 3.05 & $(0.04)$ & $(0.23)$ \\
\hline AAA & $0.58(0.06)$ & 2.33 & 2.62 & & $(0.05)$ & $(0.04)$ & & \\
\hline LGF & $1.78(0.04)$ & $(0.09)$ & $\gamma^{(0.06)}$ & & & $\downarrow$ & & \\
\hline HG & $1.16(0.23)$ & 3.58 & & & & & & \\
\hline GHG & $2.73(0.14)$ & $(0.26)$ & 3.31 & & & & & \\
\hline GGGG & $0.63(0.10)$ & 1.80 & $(0.22)$ & & & & & \\
\hline AAAA & $1.23(0.07)$ & $(0.06)$ & & & & & & \\
\hline
\end{tabular}

Figure 8. $\operatorname{Ln}\left(k_{1} / k_{2}\right)$ values calculated from abundances of the sodiated monomers in the CAD spectra of $\mathrm{Na}^{+}$-bound amino acid/peptide heterodimers. The two components of a sodiated heterodimer are connected by arrows. The corresponding $\ln \left(k_{1} / k_{2}\right)$ values are shown next to the arrows; $k_{1}$ is assigned to the dissociation that produced the more abundant sodiated monomer to have positive $\ln \left(k_{1} / k_{2}\right)$ values. Standard deviations of $\ln \left(k_{1} / k_{2}\right)$ are given in parentheses. They range between 0.03 and 0.51 and have an average value of 0.11 .

mers ( $>84 \%$ of the total fragment ion population). Adding the intensities of the consecutive dissociation products to those of the sodiated monomers did not affect the peak ratios of the sodiated monomers outside experimental error; therefore, such corrections were not undertaken [12, 22].

Fifty-three pairs of $\mathrm{Pep}_{1}-\mathrm{Na}^{+}-\mathrm{Pep}_{2}$ dimers produced acceptable CAD spectra, which allowed for the construction of a $\mathrm{Na}^{+}$affinity ladder for 24 amino acids / peptides. The ladder is presented in Figure 8. The Pep 1 and $\mathrm{Pep}_{2}$ components of the sodiated heterodimers studied are connected by arrows. The corresponding $\ln \left(k_{1} / k_{2}\right)$ values (and the standard deviations) are listed at the right side of the arrows and were calculated by assigning $k_{1}$ to the dissociation that produced the more abundant sodiated monomer. Except for AlaAlaAlaAla, all other amino acids/peptides were examined in at least three and up to seven heterodimers. Added sequential $\ln \left(k_{1} / k_{2}\right)$ values generally are in very good agreement with values obtained in one step. For example, the $\ln \left(k_{1} / k_{2}\right)$ value for the AlaAlaAla/GlyGlyGly pair resulting from direct comparison of AlaAlaAla with GlyGlyGly, $\ln \left(k_{\text {AlaAlaAla }} / k_{\text {GlyGlyGly }}\right)=1.60$ ( \pm 0.23$)$, matches within experimental error the cumulative value calculated from the stepwise comparison of the GlyGlyGly/AlaGlyGly, AlaGlyGly/AlaAlaGly, and AlaAlaGly/AlaAlaAla pairs, viz. $\ln \left(k_{\text {AlaAlaAla }} / k_{\text {GlyGlyGly }}\right)$ $=\ln \left(k_{\text {AlaGlyGly }} / k_{\text {GlyGlyGly }}\right)+\ln \left(k_{\text {AlaAlaGly }} / k_{\text {AlaGlyGly }}\right)+$ $\ln \left(k_{\text {AlaAlaAla }} / k_{\text {AlaAlaGly }}\right)=0.36( \pm 0.08)+0.70( \pm 0.04)+$ $0.58( \pm 0.06)=1.64( \pm 0.11)$. The largest discrepancy is observed for the LeuGlyPhe/GlyHisGly pair, where the $\ln \left(k_{\text {GlyHisGly }} / k_{\text {LeuGlyPhe }}\right)$ ratio from the one-step comparison is $3.58 \pm 0.26$, while the cumulative ratio calculated from the sequential LeuGlyPhe/HisGly $(1.16 \pm 0.23)$ and HisGly/GlyHisGly $(2.73 \pm 0.14)$ comparisons is $3.89 \pm 0.27$; still, these ratios match within experimental error. Such independence on the pathway in which the relative affinities are probed, supports the assumption that the apparent relative entropy, $\Delta\left(\Delta S_{\mathrm{Na}}\right.$ app $)$, of the $\mathrm{Pep}_{1}-\mathrm{Na}^{+}$and $\mathrm{Na}^{+}-\mathrm{Pep}_{2}$ bonds in the sodiated heterodimers studied here is negligible; it has been shown that apparent relative entropies are nonadditive (i.e., pathway-dependent) and cause severe disagreement between added sequential and one-step $\ln \left(k_{1} / k_{2}\right)$ ratios $[26,48,49]$. It is conceivable that entropy effects operate, but are of the same magnitude or compensate each other in one- and multistep comparisons. That this scenario would apply to all pairs investigated in one and multiple steps is, however, unlikely. Corroborating evidence that apparent relative entropies are negligible is provided by select extended kinetic method experiments, as explained below.

Since each peptide of unknown $\Delta \mathrm{H}_{\mathrm{Na}}$ cannot be paired with at least three reference bases, the extended kinetic method cannot be applied directly (i.e., on Pep- $-\mathrm{Na}^{+}-\mathrm{R}_{\mathrm{i}}$ pairs). Indirect information on the magnitude of $\Delta\left(\Delta \mathrm{S}_{\mathrm{Na}}{ }^{\text {app }}\right)$ can, nevertheless, be obtained by examining the dependence of $\ln \left(k_{1} / k_{2}\right)$ on the excitation amplitude $\left(\mathrm{V}_{p-p}\right)$ used in the CAD experiments. Varying $\mathrm{V}_{p-p}$ changes the internal energy deposited into the heterodimer ions and their $\mathrm{T}_{\text {eff }}$, and even small changes in $\mathrm{T}_{\text {eff }}$ significantly affect $\ln \left(k_{1} / k_{2}\right)$ ratios, if $\Delta\left(\Delta \mathrm{S}_{\mathrm{Na}}{ }^{\text {app }}\right)$ is considerable [12, 22, 26, 50-53].

Four pairs of peptide dimers from the bottom part of the ladder (where $\Delta\left(\Delta \mathrm{S}_{\mathrm{Na}}{ }^{\text {app }}\right)$ should be more significant), viz. GlyHis-Na ${ }^{+}-$LeuGlyPhe, GlyHis-Na ${ }^{+}-$ GlyGlyGly, AlaGlyGly-Na ${ }^{+}-$LeuGlyPhe, and GlyHisGly-Na ${ }^{+}-$GlyGlyGlyGly were subjected to CAD at different excitation energies. In the collision energy window probed $\left(\mathrm{V}_{p-p}=0.35\right.$ to $\left.0.55 \mathrm{~V}\right)$, the dimer ions yield the most abundant peaks at the lowest collision energy, while the monomer ions dominate and essentially all dimer ions have dissociated at the highest collision energy. The corresponding $\ln \left(k_{1} / k_{2}\right)$ ratios do not change appreciably with collision energy, however, and there is no meaningful correlation between these variables (Table 1). The opposite trends would have been observed if entropy effects were significant, which would make $\ln \left(k_{1} / k_{2}\right)$ ratios particularly sensitive to collision energy changes $[50,51]$. The data of Table 1 are, thus, taken as an additional indication that the apparent relative entropies of the bonds being compared in the studied heterodimers are negligible. 
Table 1. $\operatorname{Ln}\left(k_{1} / k_{2}>\right)$ values of four peptide heterodimers from CAD spectra acquired using different excitation amplitudes $\left(\mathrm{V}_{p-p}=0.35-0.55 \mathrm{~V}\right)^{\mathrm{a}}$

\begin{tabular}{|c|c|c|c|c|c|c|c|}
\hline $\ln \left(k_{1} / k_{2}\right)$ (std. dev. $)^{\mathrm{b}}$ & $0.35 \mathrm{~V}$ & $0.40 \mathrm{~V}$ & $0.45 \mathrm{~V}$ & $0.50 \mathrm{~V}$ & $0.55 \mathrm{~V}$ & Mean & $\mathrm{R}^{2}$ \\
\hline GGG-Na+ $-\mathrm{GH}$ & $0.69(0.07)$ & $0.86(0 / 02)$ & $0.84(0.02)$ & $0.86(0.05)$ & & $0.81(0.08)$ & 0.5921 \\
\hline AGG-Na ${ }^{+}-\mathrm{LGF}$ & & $3.18(0.09)$ & $3.13(0.04)$ & $3.29(0.11)$ & $3.27(0.06)$ & $3.22(0.10)$ & 0.5414 \\
\hline $\mathrm{GH}-\mathrm{Na}^{+}-\mathrm{LGF}$ & & & $2.76(0.03)$ & $2.69(0.07)$ & $2.82(0.05)$ & $2.70(0.18)$ & 0.6869 \\
\hline $\mathrm{GHG}-\mathrm{Na}^{+}-\mathrm{GGGG}$ & $0.64(0.18)$ & $0.63(0.06)$ & $0.68(0.08)$ & $0.59(0.06)$ & & $0.64(0.11)$ & 0.1220 \\
\hline
\end{tabular}

a The $\mathrm{V}_{p-p}$ range selected leads to detectable fragments and precursor peaks.

bStandard deviations are given in parentheses.

From the experimental $\ln \left(k_{1} / k_{2}\right)$ ratios displayed in Figure 8 , average cumulative $\ln \left(k / k_{\text {GlyGly }}\right)$ ratios were calculated through a least-square procedure; the resulting values and corresponding standard deviations are summarized in Table 2 and provide a quantitative measure of the $\mathrm{Na}^{+}$affinities of a series of peptides and amino acids relative to GlyGly.

\section{Conversion of the $\ln \left(k_{1} / k_{2}\right)$ Scale to $\mathrm{Na}^{+}$ Binding Affinities}

To convert the cumulative $\ln \left(k / k_{\text {GlyGly }}\right)$ scale into relative $\mathrm{Na}^{+}$affinities, the effective temperature of the dissociating heterodimers is needed, cf. eq $4 . \mathrm{T}_{\text {eff }}$ can be calibrated from the $\ln \left(k / k_{\text {Gly Gly }}\right)$ values of ligands included in Figure 8 whose $\mathrm{Na}^{+}$affinities were determined in previous studies, specifically $\operatorname{Pro}\left(\Delta \mathrm{H}_{\mathrm{Na}}=196\right.$ kJ/mol) [12], Thr (197) [12], Phe (198) [12], GlyGly (203)
[22], and $\operatorname{Trp}(210)$ [12]. Plotting $\ln \left(k / k_{\text {GlyGly }}\right)$ of these molecules (Table 2) against the corresponding $\Delta \mathrm{H}_{\mathrm{Na}}$ values leads to the regression line shown in Figure 9. The slope of this line, $1 / \mathrm{RT}_{\text {eff }}=-0.3327( \pm 0.0155)$, leads to an effective temperature of $362 \mathrm{~K}( \pm 16 \mathrm{~K})$, which was used to calculate $\mathrm{Na}^{+}$affinities relative to GlyGly, according to eq 4, as well as absolute affinities by adding the relative values to $\Delta \mathrm{H}_{\mathrm{Na}}($ GlyGly $)=203$ $\mathrm{kJ} / \mathrm{mol}$ (see Table 2). The standard deviations of the slope of the line in Figure 9 and of the $\mathrm{T}_{\text {eff }}$ derived from it are relatively small due to the excellent correlation between $\ln \left(k / k_{\text {GlyGly }}\right)$ and $\Delta \mathrm{H}_{\mathrm{Na}}$ of the five sodium ion ligands included in the plot. It is understood, however, that the effective temperature obtained this way is an estimate for all other 23 ligands listed in Table 2. Since $\mathrm{T}_{\text {eff }}$ may depend on the size and binding energy of the heterodimers subjected to CAD [21, 54, 55], the uncertainty in the $T_{\text {eff }}$ value used to calculate relative affini-

Table 2. Experimental and calculated sodium ion affinities in $\mathrm{kJ} / \mathrm{mol}$ and calculated $\mathrm{Na}^{+}$binding entropies in $\mathrm{J} / \mathrm{mol} \bullet \mathrm{K}$

\begin{tabular}{|c|c|c|c|c|c|}
\hline Amino acid or peptide & $\ln \left(k / k_{G G}\right)$ (std. dev.) & $\Delta\left(\Delta \mathrm{H}_{\mathrm{Na}}\right)^{\mathrm{a}, \mathrm{b}}$ (std. dev.) & $\Delta \mathrm{H}_{\mathrm{Na}}{ }^{\mathrm{b}}$ (std. dev.) & $\Delta \mathrm{H}_{\mathrm{Na}}$ theory & $\Delta \mathrm{S}_{\mathrm{Na}}$ theory \\
\hline$P$ & $-2.40(0.17)$ & $-7.2(1.0)$ & $196(8)$ & $195^{c}$ & $109^{c}$ \\
\hline $\mathrm{T}$ & $-2.03(0.16)$ & $-6.1(0.9)$ & $197(8)$ & & \\
\hline $\mathrm{F}$ & $-1.79(0.22)$ & $-5.4(0.9)$ & $198(8)$ & & \\
\hline GG & 0.00 & 0.0 & $203(8)$ & $203^{c}$ & $125^{\mathrm{c}}$ \\
\hline$A G$ & $0.69(0.06)$ & $2.1(0.3)$ & $205(8)$ & & \\
\hline GA & $1.24(0.07)$ & $3.7(0.5)$ & $207(8)$ & & \\
\hline AA & $1.75(0.31)$ & $5.3(1.1)$ & $208(8)$ & $207^{c}$ & $129^{c}$ \\
\hline W & $2.24(0.23)$ & $6.7(1.1)$ & $210(8)$ & & \\
\hline $\mathrm{GL}$ & $2.76(0.25)$ & $8.3(1.3)$ & $211(8)$ & & \\
\hline GF & $3.91(0.25)$ & $11.8(1.6)$ & $215(8)$ & & \\
\hline SG & $4.55(0.26)$ & $13.7(1.9)$ & $217(8)$ & & \\
\hline FG & $6.20(0.35)$ & $18.7(2.5)$ & $222(8)$ & & \\
\hline AW & $8.40(0.36)$ & $25.3(3.3)$ & $228(9)$ & & \\
\hline WA & $9.36(0.35)$ & $28.2(3.7)$ & $231(9)$ & & \\
\hline GGG & $11.37(0.37)$ & $34.2(4.4)$ & 237 (9) & $242^{d}$ & $128^{d}$ \\
\hline AGG & $11.69(0.41)$ & $35.2(4.6)$ & $238(9)$ & & \\
\hline $\mathrm{GH}$ & $12.19(0.39)$ & $36.7(4.7)$ & $240(9)$ & $245^{d}$ & \\
\hline AAG & $12.44(0.41)$ & $37.4(4.8)$ & $240(9)$ & & \\
\hline AAA & $13.03(0.41)$ & $39.2(5.1)$ & $242(9)$ & $252^{d}$ & $126^{d}$ \\
\hline LGF & $14.86(0.41)$ & $44.7(5.7)$ & $248(10)$ & & \\
\hline $\mathrm{HG}$ & $16.02(0.47)$ & $48.2(6.2)$ & $251(10)$ & $260^{d}$ & \\
\hline GHG & $18.60(0.49)$ & $56.0(7.1)$ & $259(11)$ & & \\
\hline GGGG & $19.28(0.51)$ & $58.0(7.4)$ & $261(11)$ & $277^{d}$ & $129^{d}$ \\
\hline AAAA & $20.46(0.50)$ & $61.6(7.8)$ & $265(11)$ & $278^{d}$ & $129^{d}$ \\
\hline
\end{tabular}

a Obtained using $\mathrm{T}_{\text {eff }}=362( \pm 45 \mathrm{~K})$.

${ }^{b}$ The standard deviations of the relative affinities, $\Delta\left(\Delta \mathrm{H}_{\mathrm{Na}}\right)$, were calculated from the experimental uncertainties in $\ln \left(k / k_{G / y G / y}\right)$ and $\mathrm{T}_{\text {eff }}$. The standard deviations of the absolute affinities, $\Delta \mathrm{H}_{\mathrm{Na}}$, were calculated from the standard deviations of the corresponding relative values and the uncertainty in $\Delta \mathrm{H}_{\mathrm{Na}}$ of the GlyGly anchor $( \pm 8 \mathrm{~kJ} / \mathrm{mol})$.

cMP2(full)/6-311+G(2d,2p)//MP2(full)/6-31G(d) values.

dMP2(full)/6-311+G(2d,2p)//HF/6-31G(d) values. 


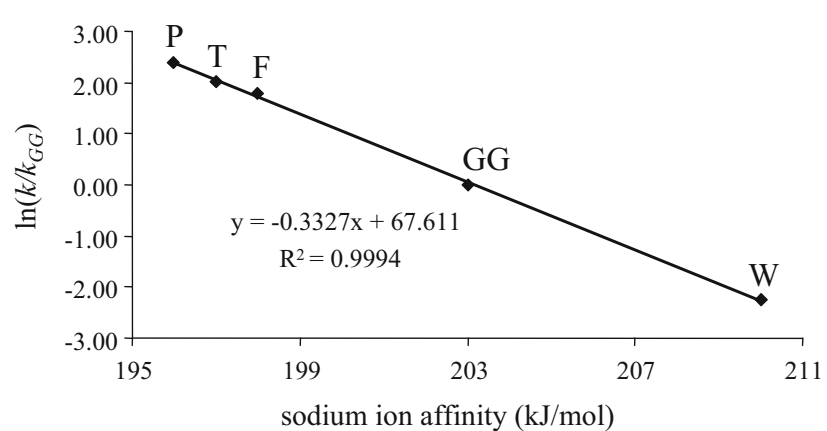

Figure 9. Plot of cumulative $\ln \left(k / k_{G l y G l y}\right)$ ratios versus $\Delta \mathrm{H}_{\mathrm{Na}}(\mathrm{Pep})$. The $\mathrm{Na}^{+}$affinities were taken from references [12] (Pro, Thr, Phe, Trp) and [22] (GlyGly).

ties was increased to $\pm 45 \mathrm{~K}$, which covers the window of effective temperatures found in our ion trap in the collision energy range used in the CAD experiments $[12,22]$.

\section{Discussion}

The agreement between our experimental and $\mathrm{ab}$ initio affinities is excellent for Pro, GlyGly, AlaAla, GlyGlyGly, and GlyHis, where both methods give values lying within $5 \mathrm{~kJ} / \mathrm{mol}$ of each other. The differences between experimental and calculated affinities are somewhat larger for AlaAlaAla, HisGly, GlyGlyGlyGly, and AlaAlaAlaAla but still fall near the corresponding experimental error limits of \pm (9 to 11$) \mathrm{kJ} / \mathrm{mol}$ (see Table 2 ). It should be mentioned at this point that the experimental uncertainty in $\Delta \mathrm{H}_{\mathrm{Na}}$ is larger than the calculated relative energies between the low-energy isomers of some Pep- $\mathrm{Na}^{+}$complexes. In such cases, possibly several isomers of Pep- $\mathrm{Na}^{+}$are probed simultaneously during the CAD experiments, as has been explained in the discussion of the computational data. The calculated Pep- $\mathrm{Na}^{+}$bond entropies (Table 2) are very similar among each other and would result in negligible relative $\mathrm{Na}^{+}$binding entropies, $\Delta\left(\Delta \mathrm{S}_{\mathrm{Na}}\right)$, for $\mathrm{Na}^{+}$-bound heterodimers. Since the corresponding apparent relative entropies, $\Delta\left(\Delta \mathrm{S}_{\mathrm{Na}}\right.$ app $)$, vary between $\Delta\left(\Delta \mathrm{S}_{\mathrm{Na}}\right)$ and zero, they are predicted to be negligible, as indeed found experimentally from the self-consistency of onestep and added sequential $\ln \left(k_{1} / k_{2}\right)$ ratios (vide supra).

It can be seen from Table 2 that increasing the peptide size dramatically increases the $\mathrm{Na}^{+}$binding energy. The sodium ion affinity is augmented by $\sim 60$ $\mathrm{kJ} / \mathrm{mol}$ if GlyGly (203 kJ/mol) is extended to GlyGlyGlyGly $(261 \mathrm{~kJ} / \mathrm{mol})$. Further, it is noteworthy that the sequential elongation Gly $\rightarrow$ GlyGly $\rightarrow$ GlyGlyGly $\rightarrow$ GlyGlyGlyGly brings upon affinity increases of 42, 34, and $24 \mathrm{~kJ} / \mathrm{mol}$ after addition of the second, third, and fourth glycyl residue, respectively; this trend is duplicated for Ala to AlaAlaAlaAla. Hence, as the size of peptides increases, the sodium ion affinities increase with a gradually decreased increment.

The four pairs of isomeric dipeptides, GlyAla and
AlaGly, GlyPhe and PheGly, AlaTrp and TrpAla, and GlyHis and HisGly were chosen to unveil the effect of sequence. Table 2 shows that except for the GlyAla/ AlaGly pair $\left(\Delta\left(\Delta \mathrm{H}_{\mathrm{Na}}\right)=-2 \mathrm{~kJ} / \mathrm{mol}\right)$, the higher sodium ion affinity is observed for the peptide with the larger side chain at the $\mathrm{N}$ terminus rather than at the $\mathrm{C}$ terminus. Since the detachment of a peptide from the heterodimer complex cleaves an electrostatic bond, any side chain that increases the electron density of the coordination site(s) will enhance the binding energy of the peptide to the metal ion, but to a different extent at the $\mathrm{N}$ and C-terminal ends. The sodium ion affinities of GlyPhe, AlaTrp, and GlyHis are smaller than those of PheGly, TrpAla, and HisGly by 7, 3, and $12 \mathrm{~kJ} / \mathrm{mol}$, respectively, indicating that the electron density around $\mathrm{Na}^{+}$is raised less if a functional side chain, which also is a potential binding site, resides at the C-terminal residue.

In both HisGly and GlyHis, there are three hydrogen bonds and in both sodium ion complexes, there is only one, due to the peptide restructuration by $\mathrm{Na}^{+}$(see Figure 6). As described above, the deformation energy required for the free peptide to reach its geometry in the complex is much smaller for HisGly than for GlyHis, leading to a larger $\mathrm{Na}^{+}$affinity for HisGly. This may be due to the $\mathrm{H}$ bond networks in the free peptides, which lead to both $\mathrm{C}=\mathrm{O}$ groups having similar orientations in HisGly (therefore nearly prepared for simultaneous binding to $\mathrm{Na}^{+}$), but not in GlyHis. It is conceivable that this effect is operative in many dipeptides involving one functional side chain able to bind strongly to sodium. If so, the stronger ligand of the two isomeric dipeptides is the one with this side chain at the $\mathrm{N}$ terminus.

To foresee what may be encountered in the determination of the sodium ion affinities of larger peptides, calculations were carried out on the heterodimer AlaAlaAla-Na ${ }^{+}-$GlyGlyGly. Starting from a structure with all six carbonyl oxygens bound to $\mathrm{Na}^{+}$, the best geometry involved hydrogen bonding between the peptides, with only four oxygens as sodium ligands (two from each peptide). This comes as no surprise since our studies on the $\mathrm{Na}^{+}$complexes of larger peptides showed that with six residues or more, only four or five oxygens are bound to $\mathrm{Na}^{+}$[56]. Thus starting with tripeptides, likely $\mathrm{Na}^{+}$-peptide binding in a dimer involves a different structure than in the monomer. Although this must change the associated binding energy, our present results show that it does not change the binding energy difference in any significant manner, presumably because the heterodimers of tri- and tetrapeptides studied herein involve very similar peptides made of Gly and Ala only. Note that if formed, the capped structure found for AlaAlaAlaAla is less crowded around $\mathrm{Na}^{+}$and should therefore be easily compatible with another peptide bound to the sodium ion. For larger peptides, and when various side chains are involved, it is not clear how far the kinetic method 
will remain valid for the accurate determination of sodium-peptide energetics.

\section{Conclusions}

We have used the kinetic method to evaluate the relative $\mathrm{Na}^{+}$affinities of nineteen simple di-, tri-, and tetrapeptides, based on the dissociations of $\mathrm{Pep}_{1}-\mathrm{Na}^{+}-$ $\mathrm{Pep}_{2}$ heterodimers. The sodium ion affinity of GlyGly $(203 \mathrm{~kJ} / \mathrm{mol})$ [22] served as an anchor to deduce the absolute affinities of these peptides. High level ab initio theory has been used to predict the sodium ion affinities of AlaAla, GlyGlyGly, GlyHis, AlaAlaAla, HisGly, GlyGlyGlyGly, and AlaAlaAlaAla. Experimental and theoretical results are in very good agreement. With the $\mathrm{Na}^{+}$-binding energy range sampled $(68.8 \mathrm{~kJ} / \mathrm{mol})$, a $T_{\text {eff }}$ of $362 \mathrm{~K}$ for the dissociating complexes yields experimental $\mathrm{Na}^{+}$affinities that agree excellently with the theoretical predictions.

Increasing the size of the peptides increases the sodium ion affinities dramatically. This study provides the sodium ion affinities of GlyGlyGly and GlyGlyGlyGly and several simple di- and tripeptides for the first time so that the augmentation in sodium ion affinity upon addition of various types of residues can be assessed. The increases in the sodium ion affinity on going from Gly to GlyGly to GlyGlyGly to GlyGlyGlyGly are 42,34 , and $24 \mathrm{~kJ} / \mathrm{mol}$, respectively. A parallel trend is observed for alanine and the analogous alanine oligomers. Given this behavior, the increase in $\mathrm{Na}^{+}$affinity on going from GlyGlyGlyGly to GlyGlyGlyGlyGly can be expected to be less than $24 \mathrm{~kJ} / \mathrm{mol}$, even though calculations predict that all five carbonyl oxygens are bound to $\mathrm{Na}^{+}$in the latter case [56]. In general, an electron-donating group in the side chain increases the binding affinity of the peptide to the metal ion and, with dipeptides, this effect is more pronounced when the side chain is located at an $\mathrm{N}$ terminal position.

\section{Acknowledgments}

The authors thank Dr. Michael J. Polce for helpful comments, and the National Science Foundation (CHE-0111128) for generous financial support. They are grateful to the Institut de Développement et de Ressources en Informatique Scientifique (IDRIS) for a generous grant of computer time (grant no. 050543).

\section{References}

1. Grossman, S. P. Thirst and Sodium Appetite-Physiological Basis; Academic Press, Inc.: San Diego, 1990; pp 177-202.

2. Michell, A. R., Ed.; The Clinical Biology of Sodium: The Physiology and Pathophysiology of Sodium in Mammals; Pergamon: Oxford, UK, 1995; p 16.

3. Skou, J. C.; Norby, J. G.; Maunsbach, A. B.; Esmann, M. Progress in Clinical and Biological Research, 268A; Alan R. Liss, Inc.: New York, 1987; pp 401-632.

4. Aidley, D. J.; Stanfield, P. R. Ion Channels: Molecules in Action; Cambridge University Press: Cambridge, 1994; pp 1-58.

5. Bojesen, J. S.; Breindahl, T.; Andersen, U. N. On the Sodium and Lithium Ion Affinities of Some $\alpha$-Amino Acids. Org. Mass Spectrom. 1993, 28, 1448-1452.

6. Klassen, J. S.; Anderson, S. G.; Blades, A. T.; Kebarle, P. Reaction Enthalpies for $\mathrm{M}^{+} \mathrm{L}=\mathrm{M}^{+}+\mathrm{L}$, where $\mathrm{M}^{+}=\mathrm{Na}^{+}$and $\mathrm{K}^{+}$and $\mathrm{L}=$ Acetamide, N-Methylacetamide, N,N-Dimethylacetamide, Glycine, and
Glycylglycine, from Determinations of the Collision-Induced Dissociation Thresholds. J. Phys. Chem. 1996, 100, 14218-14227.

7. Jockusch, R. A.; Price, W. D.; Williams, E. R. Structure of cationized arginine (Arg. $\mathrm{M}^{+}, \mathrm{M}=\mathrm{H}, \mathrm{Li}, \mathrm{Na}, \mathrm{K}, \mathrm{Rb}$, and $\mathrm{Cs}$ ) in the Gas Phase: Further Evidence for Zwitterionic Arginine. J. Phys. Chem. A 1999, 103, 9266-9274.

8. Dunbar, R. C. Complexation of $\mathrm{Na}^{+}$and $\mathrm{K}^{+}$to Aromatic Amino Acids: A Density Functional Computational Study of Cation- $\pi$ Interactions. J. Phys. Chem. A 2000, 104, 8067-8074.

9. Ryzhov, V.; Dunbar, R. C.; Cerda, B. A.; Wesdemiotis, C. Cation- $\pi$ Effects in the Complexation of $\mathrm{Na}^{+}$and $\mathrm{K}^{+}$with Phe, Tyr, and Trp in the Gas Phase. J. Am. Soc. Mass Spectrom. 2000, 11, 1037-1046.

10. Cerda, B. A.; Wesdemiotis, C. Zwitterionic Versus Charge-Solvated Structures in the Binding of Arginine to Alkali Metal Ions in the Gas Phase. Analyst 2000, 125, 657-660.

11. Talley, J. M.; Cerda, B. A.; Ohanessian, G.; Wesdemiotis, C.Alkali Metal Ion Binding to Amino Acids Versus Their Methyl Esters: Affinity Trends and Structural Changes in the Gas Phase. Chem. Eur. J. 2002, 8 , 1377-1388.

12. Kish, M. M.; Ohanessian, G.; Wesdemiotis, C. The $\mathrm{Na}^{+}$Affinities of $\alpha$-Amino Acids: Side-Chain Substituent Effects. Int. J. Mass Spec. 2003 227, 509-524

13. Gapeev, A.; Dunbar, R. C. $\mathrm{Na}^{+}$Affinities of Gas-Phase Amino Acids by Ligand Exchange Equilibrium. Int. J. Mass Spectrom. 2003, 228, 825-839.

14. Moision, R. M.; Armentrout, P. B. Experimental and Theoretical Dissection of Sodium Cation/Glycine Interactions. J. Phys. Chem. A 2002, 106, $10350-10362$

15. Hoyau, S.; Ohanessian, G.Interaction of Alkali Metal Cations $\left(\mathrm{Li}^{+}-\mathrm{Cs}^{+}\right)$ with Glycine in the Gas Phase: A Theoretical Study. Chem. Eur. J. 1998, 4, 1561-1569.

16. Hoyau, S.; Norrman, K.; McMahon, T. B.; Ohanessian, G. A Quantitative Basis for a Scale of $\mathrm{Na}^{+}$Affinities of Organic and Small Biological Molecules in the Gas Phase. J. Am. Chem. Soc. 1999, 121, 8864-8875.

17. Cerda, B. A.; Hoyau, S.; Ohanessian, G.; Wesdemiotis, C. $\mathrm{Na}^{+}$Binding to Cyclic and Linear Dipeptides. Bond Energies, Entropies of $\mathrm{Na}^{+}$ Complexation, and Attachment Sites from the Dissociation of $\mathrm{Na}^{+}$ Bound Heterodimers and Ab Initio Calculations. J. Am. Chem. Soc. 1998, 120, 2437-2448.

18. Cooks, R. G.; Wong, P. S. H. Kinetic Method of Making Thermochemical Determinations: Advances and Applications. Acc. Chem. Res. 1998, 31, $379-386$.

19. Cooks, R. G.; Koskinen, J. T.; Thomas, P. D. The Kinetic Method of Making Thermochemical Determinations. J. Mass Spectrom. 1999, 34, 85-92.

20. Feng, W. Y.; Gronert, S.; Lebrilla, C. B. Lithium and Sodium Ion Binding Energies of N-Acetyl and N-Glycyl Amino Acids. J. Am. Chem. Soc. 1999, 121, 1365-1371.

21. Cooks, R. G.; Patrick, J. S.; Kotiaho, T.; McLuckey, S. A. Thermochemical Determinations by the Kinetic Method. Mass Spectrom. Rev. 1994, 13, 287-339.

22. Kish, M. M.; Wesdemiotis, C.; Ohanessian, G. The Sodium Ion Affinity of Glycylglycine. J. Phys. Chem. B 2004, 108, 3086-3091.

23. Feller, D. A Complete Basis Set Estimate of Cation- $\pi$ Bond Strengths: $\mathrm{Na}^{+}$(Ethylene) and $\mathrm{Na}^{+}$(Benzene). Chem. Phys. Lett. 2000, 322, 543-548.

24. Feller, D.; Dixon, D. A.; Nicholas, J. B. Binding Enthalpies for Alkali Cation-Benzene Complexes Revisited. J. Phys. Chem. A 2000, 104, 11414-11419.

25. Cao, J.; Aubry, C.; Holmes, J. L. Proton Affinities of Simple Amines; Entropies and Enthalpies of Activation and Their Effect on the Kinetic Method for Evaluating Proton Affinities. J. Phys. Chem. A 2000, 104, 10045-10052.

26. Hahn, I.-S.; Wesdemiotis, C. Protonation Thermochemistry of $\beta$-Alanine. An Evaluation of Proton Affinities and Entropies Determined by the Extended Kinetic Method. Int. J. Mass Spectrom. 2003, 222, 465-479.

27. Bouchoux, G.; Djazi, F.; Gaillard, F.; Vierezet, D. Application of the Kinetic Method to Bifunctional Bases; MIKE and CID-MIKE Test Cases. Int. J. Mass Spectrom. 2003, 227, 479-496.

28. Bouchoux, G.; Buisson, D.-A.; Bourcier, S.; Sablier, M. Application of the Kinetic Method to Bifunctional Bases; ESI Tandem Quadrupole Experiments. Int. J. Mass Spectrom. 2003, 228, 1035-1054.

29. Laidler, K. J. Chemical Kinetics, 3rd ed.; Harper and Row Publishers: New York, 1987, p 112.

30. Armentrout P. B.; Rodgers, M. T. An Absolute Sodium Cation Affinity Scale: Threshold Collision-Induced Dissociation Experiments and $\mathrm{ab}$ Initio Theory. J. Phys. Chem. A 2000, 104, 2238-2247.

31. Cerda, B. A.; Wesdemiotis, C. $\mathrm{Li}^{+}, \mathrm{Na}^{+}$, and $\mathrm{K}^{+}$Binding to the DNA and RNA Nucleobases. Bond Energies and Attachment Sites from the Dissociation of Metal Ion-Bound Heterodimers. J. Am. Chem. Soc. 1996, $118,11884-11892$.

32. Cerda, B. A.; Wesdemiotis, C. Thermochemistry and Structures of $\mathrm{Na}^{+}$ Coordinated mono- and Disaccharide Stereoisomers. Int. J. Mass Spectrom. 1999, 189, 189-204.

33. Ervin, K. M. Microcanonical Analysis of the Kinetic Method. The Meaning of the "Apparent Entropy". J. Am. Soc. Mass Spectrom. 2002, 13, 435-452.

34. Wesdemiotis, C. Entropy Considerations in Kinetic Method Experiments. J. Mass Spectrom. 2004, 39, 998-1003.

35. Drahos, L.; Vékey, K. Entropy Evaluation Using the Kinetic Method: Is It Feasible?J. Mass Spectrom. 2003, 38, 1025-1042. 
36. Armentrout, P. B. Entropy Measurements and the Kinetic Method: A Statistically Meaningful Approach. J. Am. Soc. Mass Spectrom. 2000, 11 371-379.

37. McMahon, T. B.; Ohanessian, G.An Experimental and Ab Initio Study of the Nature of the Binding in Gas-Phase Complexes of Sodium Ions. Chem. Eur. I. 2000, 6, 2931-2941.

38. Cornell, W. D.; Cieplak, P.; Bayly, C. I.; Gould, I. R.; Merz, K. M. Ferguson, D. M.; Spellmeyer, D. C.; Fox, T.; Caldwell, J. W.; Kollman, P. A. A Second Generation Force Field for the Simulation of Proteins, Nucleic Acids, and Organic Molecules. J. Am. Chem. Soc. 1995, 117, 5179-5197.

39. HyperChem 6.0.; Hypercube: Gainesville, FL, 2000

40. Frisch, M. J.; Trucks, G. W.; Schlegel, H. B.; Scuseria, G. E.; Robb, M. A.; Cheeseman, J. R.; Montgomery, J. A., Jr.; Vreven, T.; Kudin, K. N.; Burant, J. C.; Millam, J. M.; Iyengar, S. S.; Tomasi, J.; Barone, V.; Mennucci, B.; Cossi, M.; Scalmani, G.; Rega, N.; Petersson, G. A. Nakatsuji, H.; Hada, M.; Ehara, M.; Toyota, K.; Fukuda, R.; Hasegawa, J.; Ishida, M.; Nakajima, T.; Honda, Y.; Kitao, O.; Nakai, H.; Klene, M.; Li, X.; Knox, J.E.; Hratchian, H. P.; Cross, J. B.; Bakken, V.; Adamo, C.; Jaramillo, J.; Gomperts, R.; Stratmann, R. E.; Yazyev, O.; Austin, A. J.; Cammi, R.; Pomelli, C.; Ochterski, J. W.; Ayala, P. Y.; Morokuma, K. Voth, G. A.; Salvador, P.; Dannenberg, J. J.; Zakrzewski, V. G.; Dapprich, S.; Daniels, A. D.; Strain, M. C.; Farkas, O.; Malick, D. K.; Rabuck, A. D.; Raghavachari, K.; Foresman, J. B.; Ortiz, J. V.; Cui, Q.; Baboul, A. G.; Clifford, S.; Cioslowski, J.; Stefanov, B. B.; Liu, G.; Liashenko, A.; Piskorz, P.; Komaromi, I.; Martin, R. L.; Fox, D. J.; Keith, T.; Al-Laham, M. A.; Peng, C. Y.; Nanayakkara, A.; Challacombe, M.; Gill, P. M. W.; Johnson, B.; Chen, W.; Wong, M. W.; Gonzalez, C.; Pople, J. A. Gaussian 03, Revision C. 02.; Gaussian, Inc.: Wallingford, CT, 2004.

41. Benzakour, M.; Mcharfi, M.; Cartier, A.; Daoudi, A. Interactions of Peptides with Metallic Cations. I. Complexes Glycylglycine- $\mathrm{M}^{+}(\mathrm{M}=$ Li, Na). J. Mol. Struct. Theochem. 2004, 710, 169-174.

42. Wong, C. H. S.; Ma, N. L.; Tsang, C. W.A Theoretical Study of Potassium Cation Binding to Glycylglycine (GG) and Alanylalanine (AA) Dipeptides. Chem. Eur. J. 2002, 8, 4909-4918.

43. Wyttenbach; T.; Bushnell, J. E.; Bowers, M. T. Salt Bridge Structures in the Absence of Solvent? The Case for the Oligoglycines. J. Am. Chem. Soc. $1998,120,5098-5103$.

44. Wyttenbach, T.; Witt, M.; Bowers, M. T. On the Stability of Amino Acid Zwitterions in the Gas Phase: The Influence of Derivatization, Proton
Affinity, and Alkali Ion Addition. J. Am. Chem. Soc. 2000, 122, 3458-3464.

45. Strittmatter, E. F.; Williams, E. R. Computational Approach to the Proton Affinities of Gly $(\mathrm{n}=1-10)$. Int. J. Mass Spectrom. 1999, 185/187, 935-948.

46. Shoeib, T.; Rodriquez, C. F.; Siu, K. W. M.; Hopkinson, A. C. A Comparison of Copper(I) and Silver(I) Complexes of Glycine, Diglycine, and Triglycine. Phys. Chem., Chem. Phys. 2001, 3, 853-861.

47. Kapota, C.; Ohanessian, G. The Low Energy Tautomers and Conformers of the Dipeptides HisGly and GlyHis and of Their Sodium Ion Complexes in the Gas Phase. Phys. Chem. Chem. Phys. 2005, 7, 3744-3755.

48. Cerda, B. A.; Wesdemiotis, C. The Relative Copper(I) Ion Affinities of Amino Acids in the Gas Phase. J. Am. Chem Soc 1995, 117, 9734-9739.

49. Lee, V. W.-M.; Li, H.; Lau, T.-C.; Guevremont, R.; Siu, K. W. M. Relative Silver(I) Ion Binding Energies of $\alpha$-Amino Acids: A Determination by Means of the Kinetic Method. J. Am. Soc. Mass Spectrom. 1998, 9, $760-766$.

50. Cheng, X.; Wu, Z.; Fenselau, C. Collision Energy Dependence of Proton-Bound Dimer Dissociation: Entropy Effects, Proton Affinities, and Intramolecular Hydrogen-Bonding in Protonated Peptides. J. Am. Chem. Soc. 1993, 115, 4844-4848.

51. Wang, Z.; Chu, I. K.; Rodriquez, C. F.; Hopkinson, A. C.; Siu, M. K. W. $\alpha, \omega$-Diaminoalkanes as Models for Bases that Dicoordinate the Proton: An Evaluation of the Kinetic Method for Estimating Proton Affinities. J. Phys. Chem. A 1999, 103, 8700-8705.

52. Schroeder, O. E.; Andriole, E. J.; Carver, K. L.; Colyer, K. E.; Poutsma J. C. Proton Affinity of Lysine Homologues from the Extended Kinetic Method. J. Phys. Chem. A 2004, 108, 326-332.

53. Wind, J. J.; Papp, L.; Happel, M.; Hahn, K.; Andriole, E. J.; Poutsma, J. C. Proton Affinity of $\beta$-Oxalylaminoalanine (BOAA): Incorporation of Direct Entropy Correction into the Single-Reference Kinetic Method. J. Am. Soc. Mass Spectrom. 2005, 16, 1151-1161.

54. Drahos, L.; Vékey, K. How Closely Related are the Effective and the Real Temperature. J. Mass Spectrom.' 1999, 34, 79-84.

55. Ervin, K. M. Microcanonical Analysis of the Kinetic Method. The Meaning of the "Effective Temperature." Int. J. Mass Spectrom. 2000, 195/196, 271-284.

56. Kapota, C. Ph. D. Dissertation, Ecole Polytechnique, Palaiseau, 2005. 